\title{
New Data on the Epidemiology of Breast Implant- Associated Anaplastic Large Cell Lymphoma
}

\author{
Paul Ionescu' ${ }^{1}$, (1) Florence Vibert ${ }^{1,2}$, (1) Shanti Amé3, (1) Carole Mathelin ${ }^{1,2,4}$
}

${ }^{1}$ Department of Surgery, Institut de cancérologie Strasbourg Europe (ICANS), Strasbourg, France

${ }^{2} \mathrm{CHRU}$, Strasbourg University Hospitals, 1 place de l'Hôpital, Strasbourg, France

${ }^{3}$ Department of Haematology and Oncology, Institut de cancérologie Strasbourg Europe (ICANS), Strasbourg, France

${ }^{4}$ Department of Functional Genomics and Cancer, Institut de Génétique et de Biologie Moléculaire et Cellulaire, Strasbourg University, Illkirch, France

\begin{abstract}
Objective: This study aimed to illustrate the epidemiological situation of breast implant-associated anaplastic large cell lymphoma (BIA-ALCL) by focusing on the changes published after 2019 and particularly the new approaches of cosmetic and reconstructive breast surgery.

Materials and Methods: Article search was performed from January 2019 to date using the PubMed database. Fourteen articles were included in the qualitative evaluation of international data. Moreover, the latest reports regarding the total number of BIA-ALCL cases and number of deaths were identified. Results: Estimates of the risk and incidence have increased significantly recently, affecting 1 in every 2,969 women with breast implants and 1 in 355 patients with textured implants after breast reconstruction. The average exposure time to diagnosis was 8 (range: 0-34) years. Approximately $80 \%$ of BIAALCL cases were diagnosed at IA-IIA stages, for which the treatment was breast implant removal, full capsulectomy, and excision of all suspected lymph nodes. Globally, at least 949 cases were reported to date.
\end{abstract}

Conclusion: At present, BIA-ALCL is an emerging pathology of interest. Data collection initiated since 2016 through different case registration databases is essential to ensure surveillance and to continue to increase the number of studies on this recently discovered pathology.

Keywords: Breast cancer, breast cancer surgery, anaplastic large cell lymphoma

Cite this article as: Ionescu P, Vibert F, Amé S, Mathelin C. New Data on the Epidemiology of Breast Implant Associated Anaplastic Large Cell Lymphoma. Eur J Breast Health 2021; 17(4): 302-307.

\section{Key Points}

- At least 949 cases of BIA-ALCL worldwide were reported to date.

- The incidence of BIA-ALCL ranges from 1 in 2,969 women with breast implants to 1 in 355 women with textured implants after breast reconstruction.

- The absolute risk of developing BIA-ALCL in women with BRCA $1 / 2$ mutation was $1 / 1,551$ at age 75 years, compared with 1/7,507 in women from the general population.

- The most widespread and accepted hypothesis is that textured implants, with their greater surface areas and increased bacterial adhesion, lead to higher rates of biofilm formation and subsequent lymphocyte activation.

- As the incidence of BIA-ALCL increases, we can expect an increasing reluctance in using textured implants in breast reconstructions, in favor of round and smooth implants, at the expense of a less natural appearance of the reconstructed breast.

- Surgeons should fully inform their patients regarding the potential risks and advantages of each implant type and obtain their consent to receive the most appropriate alternative.

\section{Introduction}

Breast implant-associated anaplastic large cell lymphoma (BIA-ALCL) is a rare form of non-Hodgkin's T-cell, CD30-positive, and anaplastic lymphoma kinase-negative lymphoma that develops around breast implants, especially those with a textured surface, used in both cosmetic surgery and reconstructive surgery $(1,2)$. The first case was reported in 1997 by Keech and Creech (3). In June 2011, the Food and Drug Administration (FDA) identified for the first time a possible association between breast implants and the development of large cell anaplastic lymphoma. In 2016, the World Health Organization admitted BIA-ALCL as a possible long-term complication of breast implants (4), and in 2017, this variant of T-cell lymphoma was included in the classification of lymphoid neoplasms (5). 
Generally, BIA-ALCL is diagnosed several years after implantation of the breast prosthesis. This is a rare but potentially serious condition, which can appear in two clinical forms: a localized form limited to the capsule [the most frequent and of good prognosis] or an infiltrating one (rarer and more serious). Only surveillance is required when the disease is localized, and explantation associated with total capsulectomy can be performed. When the disease is invasive, a systemic treatment (such as chemotherapy and radiotherapy) must be added to the surgery (6).

Breast implants are classified according to their surface: macrotextured, microtextured, nanotextured, smooth, and polyurethane surface implants. BIA-ALCL is associated with macrotextured breast implants, which led, in December 2018, to the decision of the French National Agency for the Safety of Medicines and Health Products to refuse renewal of the CE mark for Biocell and Microcell Implants (AllerganR, Dublin, Ireland). In April 2019, the French National Agency banned all macrotextured and polyurethane surface implants, a decision that affected several companies, including SebbinR (Groupe Sebbin SAS, Paris, France), PolytechR (Polytech Health \& Aesthetics, Dieburg, Germany), NagorR (GC Aesthetics, Dublin, Ireland), EurosiliconeR (GC Aesthetics, Dublin, Ireland), and AllerganR (Dublin, Ireland). On July $24^{\text {th }}, 2019$, the FDA asked AllerganR to withdraw Biocell macrotextured implants from the market to limit the occurrence of new cases of BIA-ALCL, without recommending preventive explantation for women wearing such implants (7).

In the United States, approximately 450,000 breast implants are used annually and $5 \%$ of the female population is wearing breast implants, while over 35 million women are wearing implants worldwide (8, 9). In the United States, the priority choice is round-shaped, smooth breast implant, whereas in the United Kingdom, approximately $85 \%$ of implants used are textured and have an anatomical shape. European surgeons considered several cultural and medical factors for this preference. The breast has a more natural shape with anatomical implants; with round implants, more volume in the upper pole of the breast is obtained (6). Until now, determining the elements related to disease epidemiology (incidence, prevalence, risk, etc.) has been a difficult process because of factors related to the specificity of the disease (delay to onset, nonspecific symptoms), lack of awareness of the disease from both patients and surgeons, and difficult data collection (10).

Until July 2019, BIA-ALCL was the subject of numerous studies; it has since entered a plateau phase with few new data appearing in the literature. Thus, this study aimed to create a picture of the epidemiological situation of BIA-ALCL by reviewing scientific literature on the changes after 2019 in terms of how surgeons approached cosmetic and reconstructive breast surgery.

\section{Materials and Methods}

The PubMed database was searched for articles indexed from January 2019 to April 2021. The following search term strategy was used: breast AND (implant OR prostheses) AND anaplastic AND large AND cell AND lymphoma AND (epidemiology OR risk OR incidence OR prevalence). Only original research studies or literature reviews written in English were included. Articles that do not report epidemiological data regarding BIA-ALCL and single case report articles were excluded. Other publications were searched through FDA Reports.

Furthermore, using Google Chrome browser, we looked for each country's health regulator to identify the latest reports regarding the total number of BIA-ALCL cases and number of deaths.

\section{Results}

In total, 127 articles were identified, of which 56 were excluded. One article was added through FDA Reports. Of the remaining 72 articles, 19 were considered relevant, and their full texts analyzed. Finally, 14 articles were included in the qualitative evaluation of data (Figure 1).
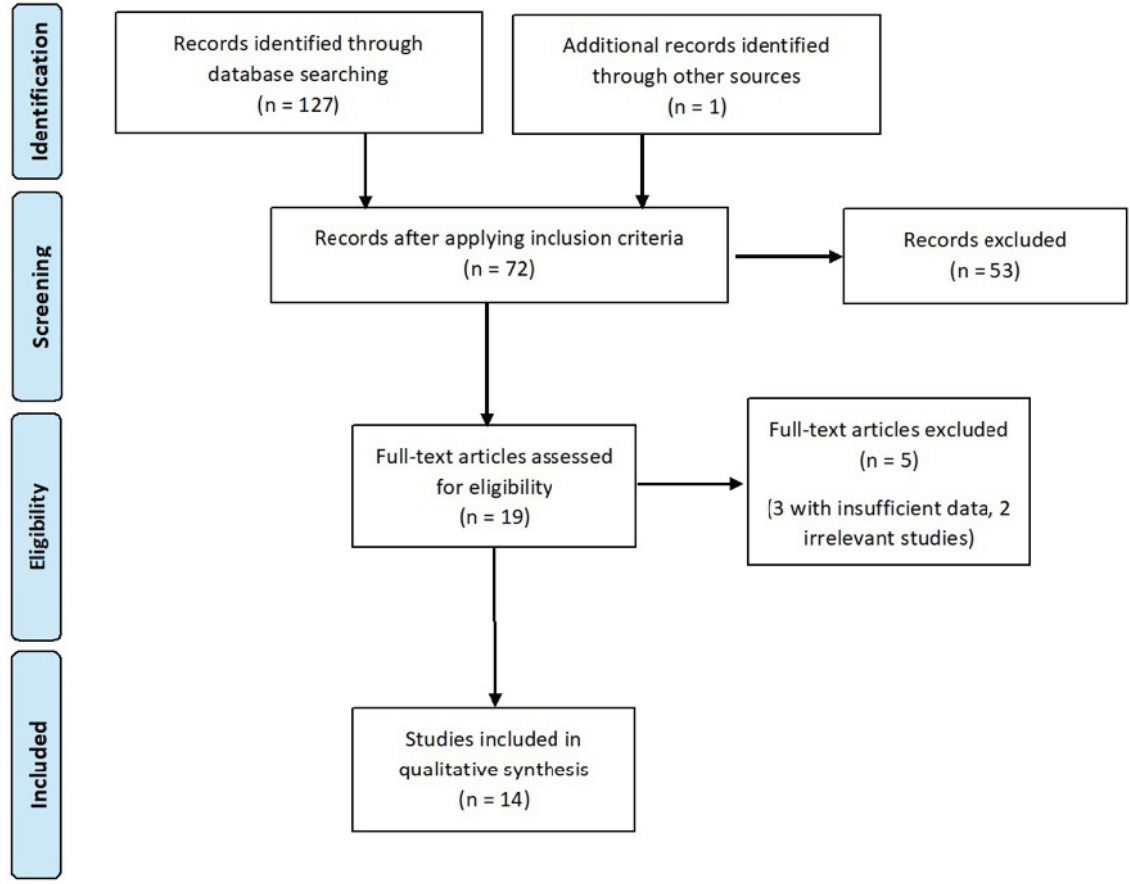

Full-text articles excluded $(n=5)$

( 3 with insufficient data, 2 irrelevant studies)

Figure 1. Flowchart 
The latest report released by the FDA in August 2020 revealed a total of 733 BIA-ALCL cases worldwide, including 384 cases in the United States, 334 outside the United States, and 15 cases of unknown location. Of the 733 patients, 36 have died, and the average age at the time of diagnosis for deceased patients was 53 years (11).

Regarding the surface of involved implants, 496 were macrotextured and 28 smooth, while the surface type was not reported in 209 cases. Of the 28 BIA-ALCL cases associated with smooth prostheses, one case documented exposure to smooth prostheses only; in the remaining cases, patients had either a history of textured breast implant exposure or the history was unrecorded. To date, no cases associated with tissue expander devices have been reported (11).

The average exposure time to diagnosis was 8 (range: $0-34$ ) years. In $50 \%$ of the cases, $26 \%$ clinically presented as a diffuse effusion around the implant, inflammation, or pain in the breast, $13 \%$ as capsular contracture, and $14 \%$ as peri-implant mass (11).

Estimates of risk and incidence have increased significantly recently, reaching 1 in 2,969 women with breast implants (12), and 1 in 355 patients with textured implants after breast reconstruction (13).

Approximately $80 \%$ of BIA-ALCL cases are diagnosed in IA-IIA stages according to the TNM classification, and these cases were treated with breast implant removal, full capsulectomy, and excision of all suspected lymph nodes. For the remaining 20\%, which are represented by more advanced stages, the treatment was associated with systemic treatment and radiotherapy (9).

Using Google, 949 BIA-ALCL cases to date were identified from Health Regulators' reports from 19 countries. In these 19 countries, a total of 32 deaths were reported. In Germany, the number of deaths could not be identified (Table 1). Standardized diagnosis and management guidelines of BIA-ALCL have been established by the National Comprehensive Cancer Network, and many countries (Table 1) use these recommendations. However, some countries have particular policies. For example, in France, the diagnosis of BIAALCL made by a pathologist must be confirmed by the national "Lymphopath" network (14). Moreover, reporting of the occurrence of BIA-ALCL by French healthcare professionals to the "Agence Nationale de Sécurité du Médicament et des Produits de Santé" is mandatory, and therapeutic options should be discussed at a national multidisciplinary consultation meeting dedicated to this disease.

\section{Discussion and Conclusion}

Throughout history, the safety of breast implants has been continually questioned (15). Silicone breast implants were invented in 1962 by Thomas Cronin and Frank Gerow and were first banned by the FDA between 1992 and 2006, a measure that did not target saline implants. In 2010, France's health regulator decided to withdraw silicone implants produced by Poly Implant Prothese (La Seyne-sur-Mer, France) from the market after investigations showed that these implants contained a cheap, low-quality silicone, usually used in constructions. Women carrying these implants were recommended to explant, with costs borne by the Ministry of Health (6). The third crisis appears to be ongoing and to affect textured implants because of the increases incidence of BIA-ALCL

\section{Incidence of BIA-ALCL}

To estimate the incidence and risk of BIA-ALCL, we should be aware of the prevalence of women with breast implants, which is difficult to quantify because of factors such as the lack of centralized databases and medical tourism $(8,9)$. The first study of an increased risk of developing BIA-ALCL (odds ratio; 18.2; 95\% confidence interval; 2.1-156.8) was conducted by De Jong et al. in 2008 (16). Subsequently, they demonstrated a link between BIA-ALCL and macrotextured breast implants, indicating a cumulative risk of disease for women wearing breast implants of 29 per million at age 50 years, 82 per million at age 70 years, and 142 per million at age 75 years (17). In a literature review published in 2019, Collett et al. (8) noted that the latter study did not differentiate textured from smooth implants, which could have led to a significant underestimation of the actual incidence and risk. Nelson et al. (18) performed a cohort study of 9,373 patients who benefited from breast reconstruction between 1991 and 2017; of 16,065 silicone breast implants used, 9,589 were textured implants. Moreover, they identified 11 cases of BIA-ALCL all in patients who had received textured implants. The average exposure time was 10.26 (range: 6.415.5) years. The overall incidence of BIA-ALCL was 1.79 per 1000 patients with textured implants (1:559) and 1.15 per 1,000 textured implants (1: 871) - the difference is caused by the fact that several patients were exposed to more than one implant in their lifetime (18). After analyzing a cohort of 3,546 patients who also benefited from

Table 1. Global number of BIA-ALCL cases and related deaths

\begin{tabular}{lccc} 
Country & $\begin{array}{c}\text { Year of } \\
\text { report }\end{array}$ & Cases & Deaths \\
\hline Argentina (30) & 2020 & 13 & 0 \\
Australia (23) & 2019 & 104 & 4 \\
Brazil (30) & 2020 & 28 & 1 \\
Canada (31) & 2019 & 31 & 1 \\
Chile (30) & 2020 & 5 & 0 \\
Colombia (30) & 2020 & 18 & 1 \\
France (32) & 2021 & 78 & 3 \\
Germany (33) & 2021 & 35 & NA \\
Italy (34) & 2021 & 72 & 2 \\
Mexico (30) & 2020 & 13 & 0 \\
Netherlands (20) & 2019 & 49 & 1 \\
New Zeeland (22) & 2019 & 6 & 1 \\
Portugal (30) & 2020 & 1 & 0 \\
PANAMA (30) & 2020 & 1 & 0 \\
Spain (30) & 2020 & 26 & 0 \\
Sweden (35) & 2018 & 6 & 2 \\
Venezuela (30) & 2020 & 1 & 0 \\
United Kingdom (36) & 2020 & 78 & 3 \\
United States (11) & 2020 & 384 & 13 \\
Total & & 949 & 32 \\
\hline & & & \\
BA-ALCL: Breast & & 13 \\
\hline
\end{tabular}

BIA-ALCL: Breast implant-associated anaplastic large cell lymphoma, NA: Not available 
breast reconstruction with textured implants, Cordeiro et al. (13) identified an overall risk of 1:355 patients after an average exposure time of 11.7 (range, 7.4-11.8) years. Moreover, $96.7 \%$ of the patients used Allergan Biocell implants (12). In France, Ruffenach et al. (19) recently reported 36 cases of BIA-ALCL, $70 \%$ of implants were made by Biocell, with an average exposure time to diagnosis of 11 years. In 2020, Santanelli di Pompeo et al. (12) collected data from European Association of Plastic Surgeons Research Council experts and found approximately 420 cases in the $28 \mathrm{EU}$ member states compared with 5,772,913 women with breast implants, with a prevalence of $1: 13,745$. In the Netherlands, which has a national database for data on procedures involving breast implants, the prevalence was 1:2,969 women with breast implants (12).

\section{Incidence of BIA-ALCL for BRCA 1 or 2 mutation carriers}

In a 2020 study conducted in the Netherlands, de Boer et al. (20) identified 15 BIA-ALCL cases after breast reconstruction with silicone prostheses. Of these cases, 26.6\% (4/15) were BRCA $1 / 2$ mutation carriers. The absolute risk of women with BRCA $1 / 2$ mutation to develop BIA-ALCL was 1:1551 at age 75 compared with 1:7507 in women from the general population (20).

\section{Effect of implant surface on the incidence of BIA- ALCL}

The type of implant surface appears to play an essential role in disease pathogenesis. Scientific evidence suggests a link between BIA-ALCL and implants with a textured surface rather than those with a smooth surface, and the risk appears to increase in implants with a more robust textured surface (15). Jones et al. (21) performed measurements of the area and roughness of the implant surface and proposed a new classification of breast implants in $4^{\circ}$. Their study showed a significant increase in bacterial growth over 24 hours on the surface of grade 4 implants and significantly slower bacterial growth in grade 1 implants (21). In 2019, Magnusson et al. (22) published an update on the epidemiological situation in Australia and New Zealand and reported that $78.9 \%$ of BIA-ALCL cases occurred in patients with grade 3 or 4 surface implants. All patients in whom the disease occurred following exposure to grade 1 surface implants had a history of exposure to highgrade surface implants (22). In another Australian study of 104 cases, Deva et al. (23) demonstrated a link between increased incidence of BIA-ALCL and use of rough surface implants $(\mathrm{p}=0.0001)$ and those with a large surface area $(p=0.0007)$. In addition, the risk of developing BIA-ALCL varies between 1:1947 for Silimed Polyurethane implants (Mapamed-Silimed, Brasil, Brazil) and 1:36730 for Siltex-imprinted textured devices (Mentor, Santa Barbara, CA, USA) (24).

\section{Different theories about the etiology of BIA-ALCL}

Several theories have been proposed to explain the etiology of BIAALCL. Some authors believe that silicone degradation products would trigger an immune response via T helper cells (24). However, the most widespread and accepted hypothesis states that textured implants, with their greater surface areas and increased bacterial adhesion, lead to higher rates of biofilm formation and subsequent lymphocyte activation (23). Following the withdrawal from the market of Biocell macrotextured implants (Allergan), Danino et al. (25) identified 1,260 patients with this type of implant at the University of Montreal Hospital Center in Canada between 1960 and
2006. Of these patients, 92 opted for implant removal. No cases of BIA-ALCL have been identified, which, according to the author, raises the notion of clustering of cases that affect disease prevalence from a geographical perspective and supports the hypothesis of an infectious trigger (25). In 2017, Adams et al. (26) examined a cohort of 21,650 patients in whom 42,035 Biocell textured implants were used. After an average follow-up duration of 11.7 years, the 8 plastic surgeons who participated in the study and who complied with at least $13 / 14$ points of the bacterial contamination avoidance plan proposed by Deva et al. (23) did not identify BIA-ALCL cases since 2013 (26). The theory that an infection triggers the disease would mean that the cause is related to the technique used by surgeons, a notion disagreed by several authors who believed that the discovery of a cluster of cases by certain surgeons does not indicate a lack of technical skills, but most likely an increased awareness for its diagnosis $(12,27)$.

\section{New approaches of cosmetic and reconstructive breast surgery}

Breast prosthesis manufacturers reported that $70 \%-80 \%$ of implants sold in the United Kingdom are textured, while $70 \%-80 \%$ of them sold in the United States are smooth (10). Regarding the surgeons' preferences for a certain type of surface of breast implants, Nelson et al. (18) noted that between 1991 and 2009, in the Memorial Sloan Kettering Cancer Center in the United States, textured implants by far exceeded smooth implants. Since 2009, a balance between the two types of implants was noticed, and after 2011, surgeons preferred smooth implants over textured implants (18). A multinational survey conducted in Europe and published in 2020 showed that most surgeons $(70 \%)$ prefer textured implants and that only $29 \%$ of those who changed their preferences in terms of the implant surface and manufacturing company did so to prevent the occurrence of BIAALCL (28). A Portuguese study by Cunha et al. (10) showed that of 57 (27 state and 28 private) hospitals, one hospital mostly used breast implants with a smooth surface, whereas others preferred textured implants (10). This preference in Europe can be explained by the relatively low rates of capsular contracture and implant rotation associated with textured implants. Moreover, patients who require breast reconstruction look for a more natural shape of the breast, which is more likely to be obtained by using a shaped breast implant, which is always textured to allow better adhesion of the device to the surrounding tissues and thus prevent rotation (2).

Evaluation of data provided by the Dutch Breast Implant Registry showed that, before 2019, only $1 \%$ of implants used for breast reconstruction were smooth, while in subsequent years, the usage rate of smooth implants increased seven times. In cosmetic surgery, the usage rate of smooth implants increased from $7 \%$ to $11 \%$ after 2019 , while textured implants were used in $88 \%$ of cases since 2019 , compared with $91 \%$ before 2019 (29).

As the incidence of BIA-ALCL cases increased, we can expect an increasing reluctance to the use of textured implants in breast reconstructions, in favor of round, smooth implants, at the expense of a less natural appearance of the reconstructed breast. This could lead to a decrease in patient satisfaction and, in the long term, even to a decrease in the demand for breast reconstruction using prosthesis. Surgeons should fully inform their patients about the potential risks and advantages of each implant type when choosing alternatives more likely to be suitable for them. 
In conclusion, BIA-ALCL is an emerging pathology of current interest. Although the symptoms, management, and follow-up have clearly been defined in most countries, its physiopathology remains unclear. As early as 2015, an inflammatory origin of BIA-ALCL was related to the implant surface. More recently, an infectious origin was evoked, in particular by the presence of a biofilm chronically activating lymphocytes. Data collection initiated since 2016 through different case registration databases is essential to ensure surveillance and continue research into this recently discovered pathology.

Peer-review: Externally peer-reviewed.

\section{Authorship Contributions}

Concept: F.V., C.M.; Design: S.A., C.M.; Data Collection and/or Processing: P.I., F.V.; Analysis and/or Interpretation: P.I., C.M.; Literature Search: P.I., F.V.; Writing: P.I., S.A., C.M.

Conflict of Interest: No conflict of interest was declared by the authors.

Financial Disclosure: The authors declared that this study received no financial support.

\section{References}

1. Blombery P, Thompson ER, Prince HM. Molecular drivers of breast implant-associated anaplastic large cell lymphoma. Plast Reconstr Surg 2019; 143: 59S-64S. (PMID: 30817557) [Crossref]

2. Leberfinger AN, Behar BJ, Williams NC, Rakszawski KL, Potochny JD, Mackay DR, et al. Breast implant-associated anaplastic large cell lymphoma: a systematic review. JAMA Surg 2017; 152: 1161-1168. (PMID: 29049466) [Crossref]

3. Keech JA, Jr., Creech BJ. Anaplastic T-cell lymphoma in proximity to a saline-filled breast implant. Plast Reconstr Surg 1997; 100: 554-555. (PMID: 9252643) [Crossref]

4. Swerdlow SH, Campo E, Pileri SA, Harris NL, Stein H, Siebert R, et al. The 2016 revision of the World Health Organization classification of lymphoid neoplasms. Blood 2016; 127: 2375-2390. (PMID: 26980727) [Crossref]

5. WHO classification of tumours of haematopoietic and lymphoid tissues. Available at: http://archive.org/details/whoclassificatio00swer [Crossref]

6. Mathelin C. Un nouveau scandale des prothèses mammaires ? [A new breast implant scandal?]. Gynecol Obstet Fertil Senol 2019; 47: 327-328. [Article in French] (PMID: 30904139) [Crossref]

7. Groth AK, Graf R. Breast implant-associated anaplastic large cell lymphoma (BIA-ALCL) and the textured breast implant crisis. Aesthetic Plast Surg 2020; 44: 1-12. (PMID: 31624894) [Crossref]

8. Collett DJ, Rakhorst H, Lennox P, Magnusson M, Cooter R, Deva AK. Current risk estimate of breast implant-associated anaplastic large cell lymphoma in textured breast implants. Plast Reconstr Surg 2019; 143(3S A review of breast implant-associated anaplastic large cell lymphoma): 30S-40S. (PMID: 30817554) [Crossref]

9. Marra A, Viale G, Pileri SA, Pravettoni G, Viale G, De Lorenzi F, et al. Breast implant-associated anaplastic large cell lymphoma: a comprehensive review. Cancer Treat Rev 2020; 84: 101963. (PMID: 31958739) [Crossref]

10. Cunha A, Horta R, Barreiro D. Epidemiological profile in Portugal of breast implant-associated anaplastic large cell lymphoma: a cross-sectional study. Acta Med Port 2021 Jan 29. doi: 10.20344/amp.14055. [Epub ahead of print]. (PMID: 33512315) [Crossref]

11. FDA Updates Analysis of Medical Device Reports of Breast Implant Illness and Breast Implant-Associated Lymphoma. Available at: https:// medical-device-reports-breast-implant-illness-and-breast-implantassociated [Crossref]

12. Santanelli di Pompeo F, Sorotos M, Clemens MW, Firmani G; European Association of Plastic Surgeons (EURAPS) Committee on Device Safety and Development. Breast implant-associated anaplastic large cell lymphoma (BIA-ALCL): review of epidemiology and prevalence assessment in Europe. Aesthet Surg J 2021; 41: 1014-1025. (PMID: 33022037) [Crossref]

13. Cordeiro PG, Ghione P, Ni A, Hu Q, Ganesan N, Galasso N, et al. Risk of breast implant associated anaplastic large cell lymphoma (BIAALCL) in a cohort of 3546 women prospectively followed long term after reconstruction with textured breast implants. J Plast Reconstr Aesthet Surg 2020; 73: 841-846. (PMID: 32008941) [Crossref]

14. Laurent C, Baron M, Amara N, Haioun C, Dandoit M, Maynadie M, et al. Impact of expert pathologic review of lymphoma diagnosis: study of patients from the French lymphopath network. J Clin Oncol 2017; 35 : 2008-2017. (PMID: 28459613) [Crossref]

15. Cardoso MJ, Wyld L, Rubio IT, Leidenius M, Curigliano G, Cutuli B, et al. EUSOMA position regarding breast implant associated anaplastic large cell lymphoma (BIA-ALCL) and the use of textured implants. Breast 2019; 44: 90-93. (PMID: 30703669) [Crossref]

16. de Jong D, Vasmel WL, de Boer JP, Verhave G, Barbe E, Casparie MK, et al. Anaplastic large-cell lymphoma in women with breast implants. JAMA 2008; 300: 2030-2035. (PMID: 18984890) [Crossref]

17. de Boer M, van Leeuwen FE, Hauptmann M, Overbeek LIH, de Boer JP, Hijmering NJ, et al. Breast implants and the risk of anaplastic largecell lymphoma in the breast. JAMA Oncol 2018; 4: 335-341. (PMID: 290302687) [Crossref]

18. Nelson JA, Dabic S, Mehrara BJ, Cordeiro PG, Disa JJ, Pusic AL, et al. Breast implant-associated anaplastic large cell lymphoma incidence: determining an accurate risk. Ann Surg 2020; 272: 403-409. (PMID: 32694446) [Crossref]

19. Ruffenach L, Bruant-Rodier C, Goldammer F, Ramelli E, Bodin F, Dissaux C. Trente-six cas français de lymphomes anaplasiques à grandes cellules associés aux implants mammaires. Que savons-nous sur leur histoire prothétique ? [Thirty-six (36) French cases of breast implantassociated anaplastic large cell lymphoma (BIA-ALCL): what do we know about their prosthetic histories, and what conclusions may be drawn?]. Ann Chir Plast Esthet 2019; 64: 285-292. [Article in French] (PMID: 31331683) [Crossref]

20. de Boer M, Hauptmann M, Hijmering NJ, van Noesel CJM, Rakhorst HA, Meijers-Heijboer HEJ, et al. Increased prevalence of BRCA1/2 mutations in women with macrotextured breast implants and anaplastic large cell lymphoma of the breast. Blood 2020; 136: 1368-1372. (PMID: 32452517) [Crossref]

21. Jones P, Mempin M, Hu H, Chowdhury D, Foley M, Cooter R, et al. The functional influence of breast implant outer shell morphology on bacterial attachment and growth. Plast Reconstr Surg 2018; 142: 837849. (PMID: 30252806) [Crossref]

22. Magnusson M, Beath K, Cooter R, Locke M, Prince HM, Elder E, et al. The epidemiology of breast implant-associated anaplastic large cell lymphoma in Australia and New Zealand Confirms the highest risk for grade 4 surface breast implants. Plast Reconstr Surg 2019; 143: 12851292. (PMID: 30789476) [Crossref]

23. Deva AK, Adams WP, Jr., Vickery K. The role of bacterial biofilms in device-associated infection. Plast Reconstr Surg 2013; 132: 1319-1328. (PMID: 23924649) [Crossref]

24. Loch-Wilkinson A, Beath KJ, Magnusson MR, Cooter R, Shaw K, French J, et al. Breast implant-associated anaplastic large cell lymphoma in australia: a longitudinal study of implant and other related risk factors. Aesthet Surg J 2020; 40: 838-846. (PMID: 31738381) [Crossref] 


\section{Ionescu et al. Epidemiology of Anaplastic Large Cell Lymphoma-Associated with Breast Implants}

25. Danino MA, Dao L, Retchkiman M, Matetsa E, Iezzoni J, Bou-Merhi JS. Analysis of allergan's biocell implant recall in a major university breast center. Plast Reconstr Surg Glob Open 2020; 8: e2906. (PMID: 32766057) [Crossref]

26. Adams WP, Jr., Culbertson EJ, Deva AK, M RM, Layt C, Jewell ML, et al. Macrotextured breast implants with defined steps to minimize bacterial contamination around the device: experience in 42,000 implants. Plast Reconstr Surg 2017; 140: 427-431. (PMID: 32766057) [Crossref]

27. Swanson E. A 1-point plan to eliminate breast implant-associated anaplastic large-cell lymphoma. Ann Plast Surg 2018; 80: 465-466. (PMID: 29521653) [Crossref]

28. Villarroya-Marquina I, Moshrefi S, Sheckter C, Lee GK. European attitudes and outcomes regarding breast implant-associated anaplastic large cell lymphoma: a multinational survey. Aesthetic Plast Surg 2020; 44: 1387-1395. (PMID: 32367324) [Crossref]

29. Keuter Xavier MM, Becherer B, Bommel A, Vrolijk J, Hoornweg M, et al. Annual Report DBIR 2019 Project : Third extended report of the Dutch Breast Implant Registry. DUTCH BREAST IMPLANT REGISTRY (DBIR); 2019. Available at: https://dica.nl/media/2560/DBIR\%20 Annual\%20Report\%202019\%20(2).pdf [Crossref]

30. José Sainz-Arregui, Pérez MdMV. Trend in the use of breast implants of Ibero Latin American plastic surgeons. FILACP study 2010-2020. Cirugía Plástica Ibero-Latinoamericana 2020; 46: 125-140. [Crossref]
31. BIA ALCL Letter to Membership. Available at: https://csaps.ca/ wp-content/uploads/2019/12/BIA-ALCL-Letter-to-MembershipFINAL-2019-1203.pdf [Crossref]

32. Dossier thématique - Surveillance de marché des implants mammai - ANSM Available at: https://ansm.sante.fr/dossiers-thematiques/ surveillance-de-marche-des-implants-mammaires [Article in French] [Crossref]

33. BfArM - Empfehlungen des BfArM - Möglicher Zusammenhang zwischen Brustimplantaten und der Entstehung eines anaplastischen großzelligen Lymphoms (ALCL) Available at: https://www.bfarm.de/SharedDocs/ Risikoinformationen/Medizinprodukte/DE/Brustimplantate_ALCL_ FDA.html [Article in German] [Crossref]

34. Protesi mammarie e Linfoma anaplastico a grandi cellule (ALCL) Available at: http://www.salute.gov.it/portale/temi/p2_6.jsp?lingua=ita liano\&id=4419\&area=dispositivi-medici\&menu=vigilanza $[$ Article in Italian] [Crossref]

35. Hedén P, Stark B. Bröstsvullnad och förhårdnad efter implantation kan vara BIA-ALCL. Läkartidningen 2018; 115: 1-4. [Crossref]

36. Breast implants and Anaplastic Large Cell Lymphoma (ALCL). Available at: https://www.gov.uk/guidance/breast-implants-and-anaplastic-largecell-lymphoma-alcl [Crossref] 